\title{
A white-bluish plaque with rapid growth after palpation
}

\author{
Belén Lozano-Masdemont ${ }^{1}$, Isabel Polimón-Olabarrieta ${ }^{1}$, Berta Pérez-Tato ${ }^{1}$, \\ Cristina Diego-Hernández ${ }^{2}$
}

\begin{abstract}
1 Department of Dermatology, Hospital Universitario de Móstoles, Móstoles, Madrid, Spain 2 Department of Pathology, Hospital Universitario de Móstoles, Madrid, Spain
\end{abstract}

Key words: dermatofibroma, fibrous histiocytoma, aneurysmal dermatofibroma, dermoscopy

Citation: Lozano-Masdemont B, Polimón-Olabarrieta I, Pérez-Tato B, Diego-Hernández C. A white-bluish plaque with rapid growth after palpation. Dermatol Pract Concept. 2018;8(4):337-339. DOI: https://doi.org/10.5826/dpc.0804a19

Received: March 16, 2018; Accepted: June 3, 2018; Published: October 31, 2018

Copyright: (92018 Lozano-Masdemont et al. This is an open-access article distributed under the terms of the Creative Commons Attribution License, which permits unrestricted use, distribution, and reproduction in any medium, provided the original author and source are credited.

Funding: None.

Competing interests: The authors have no conflicts of interest to disclose.

All authors have contributed significantly to this publication.

Corresponding author: Belén Lozano-Masdemont, MD, Department of Dermatology, Hospital Universitario de Móstoles, Río Júcar, s/n, 28935 Móstoles, Madrid, Spain. Email: belenmasdemont@gmail.com

\section{Case Presentation}

A 70-year-old woman presented with an asymptomatic pigmented lesion located on the right shoulder that had first been noticed about 1 year prior. She reported no previous trauma. On examination, there was a depressed, smooth, firm, white and bluish plaque that measured about $15 \mathrm{~mm}$ in diameter (Figure 1). The dimple sign was present; it was not painful. Immediately after clinical palpation, the plaque started to grow in size and became painful (Figure 2).

On dermoscopy, a blue-violaceous homogeneous area was observed in the center of the lesion surrounded by a whitish homogeneous area (Figure 3). A delicate pigment network was found at the periphery of the lesion, over the whitish area, and scattered dotted and linear vessels were also present. The lesion was completely excised. Histopathologic examination revealed a very cellular dermal neoplasm composed of interlacing spindle cells with vesicular nuclei and eosinophilic cytoplasm within collagen bundles arranged in a storiform pattern. Blood-filled spaces that lacked an endothelial lining, multifocal hemorrhage and hemosiderin deposition were

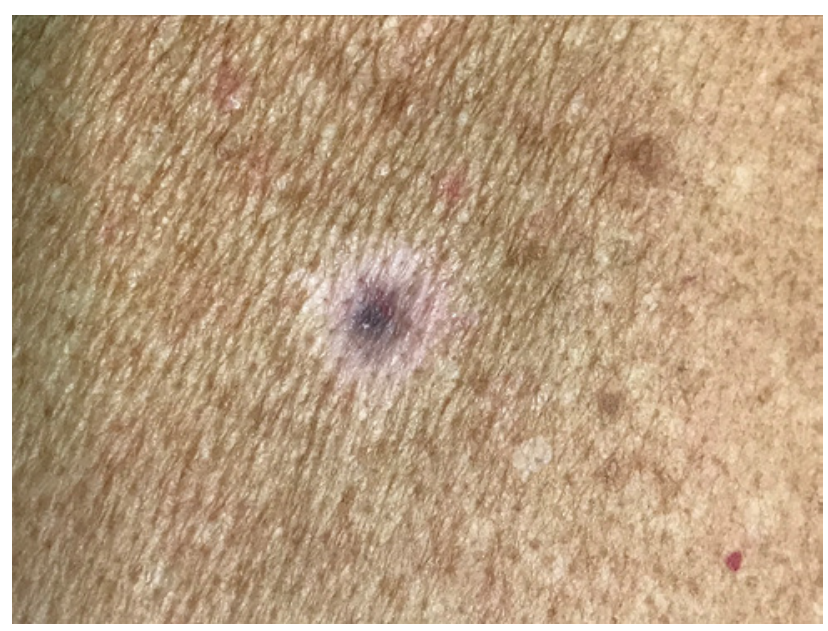

Figure 1. Clinical image. A depressed, smooth, firm, white and bluish plaque, about $15 \mathrm{~mm}$ in diameter, on the right shoulder. The dimple sign was present. [Copyright: (C2018 Lozano-Masdemont et al.]

intermixed with the collagen bundles. (Figure 4). Spindle cells were positive for factor XIIIa and negative for CD34, actin, desmin, S-100, melan-A and HMB45. A diagnosis of aneurysmal dermatofibroma was established. 


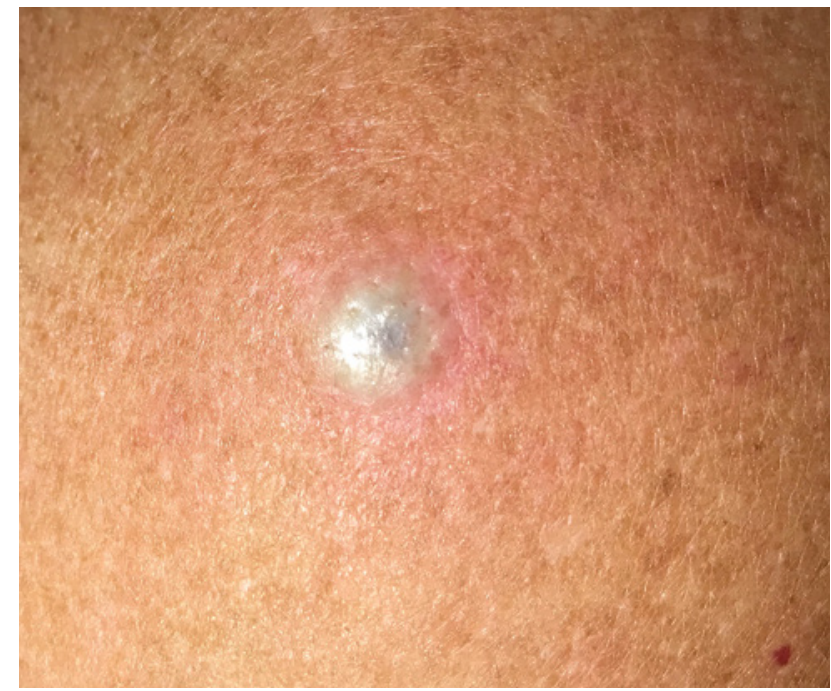

Figure 2. Clinical image. The same plaque grew in size after clinical palpation. [Copyright: (O2018 Lozano-Masdemont et al.]

\section{Discussion}

Dermatofibroma is a benign dermal fibrohistiocytic tumor, mainly found on the lower limbs that presents with raised, hyperkeratotic nodules smaller than $2 \mathrm{~cm}$, with a reddishbrown surface. It may be solitary, multiple, clustered and giant.

Aneurysmal dermatofibroma represents about $1.7 \%$ of all dermatofibromas, commonly presenting as a solitary nodule on the limbs of middle-aged adults [1]. It is usually larger than a typical dermatofibroma $(0.5-4 \mathrm{~cm})$. It may be associated with pain or rapid growth due to hemorrhage.

The characteristic histological feature is the presence of hemorrhagic, cleft-like, and cystic spaces without an endothelial lining. Adjacent solid areas show the usual features of dermatofibroma, often more cellular. Multifocal interstitial hemorrhage and intra- and extracellular hemosiderin deposition are prominent [1]. Hemosiderotic dermatofibroma could be a precursor stage in its formation, due to slow, continuous extravasation of blood from capillaries, especially in the highly cellular areas containing a poorly developed reticulin network [1].

Dermoscopically, hemosiderotic and aneurysmal dermatofibromas are characterized by a blue-yellowish to redbrownish pigmented homogeneous area. The histopathological correlation could be the prominent blood-filled spaces and intra- and extracellular hemosiderin deposition. A yellowish homogeneous area seen at the periphery of the lesion could be caused by hemosiderin deposits or foamy giant cells and macrophages [2]. Other reported dermoscopic features are white linear and homogeneous structures caused by pronounced fibrosis within the papillary dermis [2]. Moreover, a delicate pigment network, scaly surface, and dotted, comma, and linear irregular and dilated vessels may be present [2].

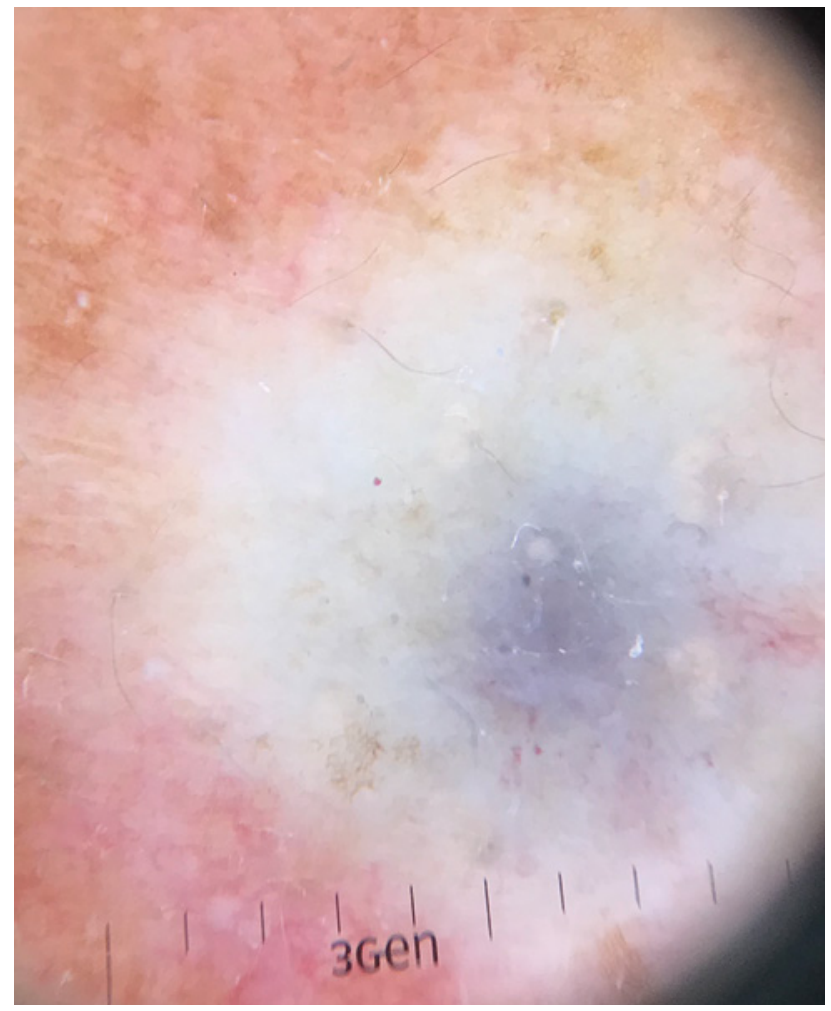

Figure 3. Dermoscopic image. A blue-violaceous homogeneous area surrounded by a whitish homogeneous area were the main features. A delicate pigment network was found at the periphery of the lesion over the whitish area and scattered dotted and linear vessels were also present. [Copyright: (O2018 Lozano-Masdemont et al.]

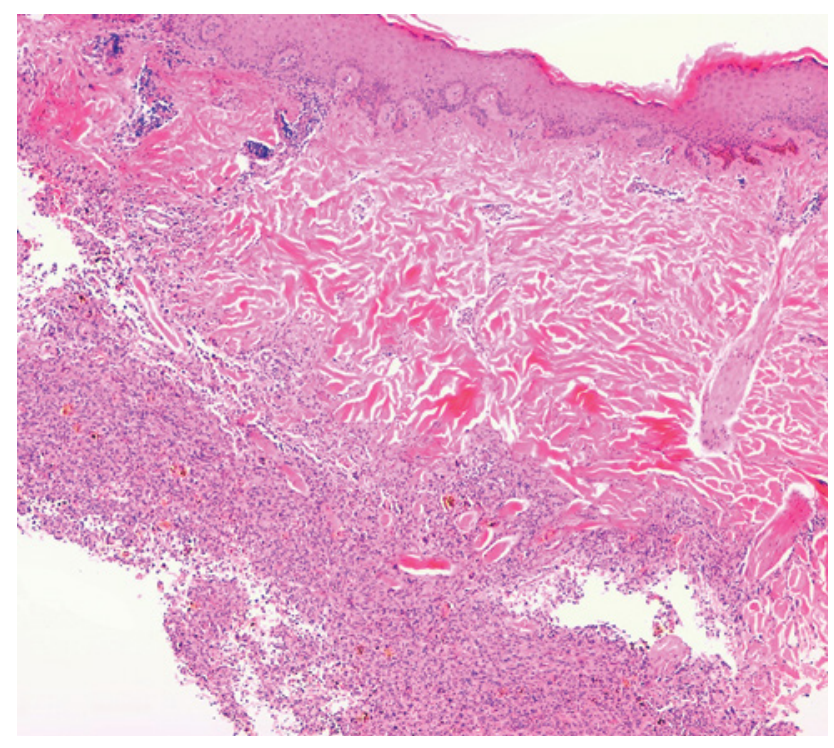

Figure 4. Histopathologic examination (hematoxylin and eosin stain, $4 \mathrm{x}$ ) revealed a dermal neoplasm, composed of interlacing spindle cells with vesicular nuclei and eosinophilic cytoplasm within collagen bundles arranged in a storiform pattern. Blood-filled spaces that lacked an endothelial lining, multifocal hemorrhage and hemosiderin deposition were intermixed with the collagen bundles. [Copyright: @2018 Lozano-Masdemont et al.] 
The most important differential diagnosis is melanoma, since there is a significant association with a melanoma-like pattern/vascular tumor-like pattern on dermoscopy [1].

Due to diagnostic uncertainty and painful episodes of hemorrhage, a complete surgical excision of aneurysmal dermatofibroma is the norm. The rate of recurrence is around $19 \%$ [1].

\section{References}

1. Ferrari A, Argenziano G, Buccini P, et al. Typical and atypical dermoscopic presentations of dermatofibroma. J Eur Acad Dermatol Venereol. 2013;27(11):1375-1380.

2. Zaballos P, Llambrich A, Ara M, Olazarán Z, Malvehy J, Puig S. Dermoscopic findings of haemosiderotic and aneurysmal dermatofibroma: report of six patients. Br J Dermatol. 2006;154(2):244250 . 